\title{
Apostillas a un diálogo (entreoído) sobre la locura en el Quijote de 1615
}

\author{
Notes to a (Half-heard) Dialogue \\ about Madness in the Quixote from 1615
}

\author{
GuSTAVo Illades
}

Maurice Molho y Margit Frenk dialogaron de viva voz hace un cuarto de siglo sobre la locura de don Quijote en la Segunda parte de la novela cervantina. En el presente artículo reconstruyo dicho diálogo a partir de las publicaciones subsecuentes que ambos hispanistas dedicaron al tema. Luego de describir sus estudios, identifico posibles influjos mutuos, correspondencias y divergencias. Por último, intento armonizar sus hallazgos mediante un análisis propio según el cual: a) el protagonista muere loco - como sugiere Frenk-, pero con otra versión de locura; y b) no es el personaje - como propone Molho- sino el libro el que accede a la razón precartesiana. Ambas propuestas convergen en la identificación del lector implícito: el consabido lector crédulo de ficciones caballerescas y a un tiempo el creyente crédulo.

PALABRAS CLAVE: locura, razón, muerte de don Quijote, Margit Frenk, Maurice Molho.

A quarter of century ago, Maurice Molho and Margit Frenk talked in person about don Quixote's madness in the Second part of Cervantes' novel. In the present article I reconstruct this dialogue from the subsequent publications that both hispanists dedicated to the topic. After describing their studies, I identify possible mutual influences, correspondences and divergences between them. Finally, I try to harmonize their findings through a personal analysis which states: a) The protagonist dies insane - as Frenk suggests-, but with a different kind of madness; and b) It is not the character - as Mohlo proposes- 
but the book instead which gains access to the pre-Cartesian rationality. Both proposals converge in the identification of the implicit reader: the well-known gullible reader of knightly fiction, and at the same time the gullible believer.

KEYWORDS: madness, rationality, death of don Quixote, Margit Frenk, Maurice Molho.

Fecha de recepción: 9 de mayo de 2015

Fecha de aceptación: 24 de agosto de 2015 
Gustavo ILlades

Universidad Autónoma Metropolitana-Iztapalapa

gillades@hotmail.com

\section{Apostillas a un diálogo (entreoído) sobre la locura en el Quijote de 1615}

Inicio con una anécdota. En 1988 Maurice Molho impartió un curso sobre el Quijote en El Colegio de México al que asistí como oyente. Cierta mañana se impuso el silencio cuando una distinguida hispanista abrió la puerta del aula y luego tomó discretamente asiento entre los alumnos. Era Margit Frenk. El tema de la clase fue la locura de don Quijote en la Segunda parte de la novela, locura no delirante según Molho y por lo mismo distinta de la que recorre al Quijote de 1605. Terminada la sesión, ambos profesores se alejaron conversando por alguno de los pasillos. Sólo pude escuchar que ella decía que en el episodio del barco encantado el personaje parecía recaer en los delirios de la Primera parte. La respuesta de Molho, inquietante para mí, se la llevó el viento.

A vuelta de año apareció un Homenaje a Margit Frenk publicado por la Universidad Autónoma Metropolitana. Se entenderá la expectación que me causó encontrar en el volumen un estudio de Molho dedicado a la homenajeada, cuyo título además anunciaba la respuesta —esta vez in extenso - que no pude escuchar aquella mañana: "Ilusión y engaño de los sentidos en Don Quijote (De los molinos de viento al barco encantado)". Antes de centrarme en él, haré referencia a un estudio anterior (“¿Por qué se vuelve loco don Quijote?”, 1988) que descifra la dinámica que Cervantes imprime a la locura. Veamos: 
Lo fundamental en ese período del pensamiento europeo [escribe Molho], es la invención de la razón moderna, el descubrimiento de que lo real y lo racional son coincidentes en el horizonte del espíritu: ésa es, en efecto, la lección de las Meditaciones metafisicas. [...] [El Quijote, en cambio, es] un momento singularmente crítico en la historia de la razón. [...] La razón, en efecto, sólo alcanza a definirse expulsando de sí todo lo que no es ella, y que es lo que estorba y oscurece el intelecto de don Quijote. [...] Esa no-locura desde la cual es posible considerar la locura —aunque sea momentáneamente-, es lo que se llamará [en la época] cordura, discreción, juicio y también razón, que es voz difícil cuya historia y cuyo análisis están aún por hacer. [En último término,] el Quijote es una busca agónica de la razón (Molho [1988] 2005a: 350).

De donde se sigue que leemos la novela a partir, inevitablemente, de una posición postcartesiana, lo cual conduce a un modelo que opone locura a razón, siendo que deberíamos leer a partir de un modelo dinámico que mezcle con proporciones variables "locura y no-locura" o "locura positiva y locura negativa [o crítica]", esto es:

razón

locura + no-locura

Para Molho la ecuación da cuenta de todos los juegos intelectuales del libro, singularmente de la "evacuación en el segundo Quijote de las locuras alucinatorias". En suma, la razón que obra es impura "por efecto de la locura que la invade y por lo mismo le prohíbe acceder de modo libre y constante a la verdad, es decir a lo real" (351-352). Puesto que el Quijote se rige por la preceptiva aristotélica, la verdad será la de la experiencia como acontecimiento, como hecho que obra en la historia, por lo que la ficción viene a ser contra-historia. Y si los dos grandes temas del libro son la locura y la literatura, la intersección entre ambos ocurre necesariamente en la ficción de caballerías — la más emparentada con la historia en la mentalidad de la época- a través del personaje del loco. Así, en la base del Quijote se halla una "sencillísima proposición"; a saber, que la locura es a la razón lo que la ficción a la historia: 


$$
\frac{\text { razón }}{\text { locura }} \quad \frac{\text { historia }}{\text { ficción }}
$$

A diferencia de don Diego de Miranda, para quien la ficción de caballerías es un problema moral (II, 16), don Quijote enfrenta un problema epistemológico: ¿mienten las historias de caballerías? No, dirá, porque son historias y por ello no pertenecen al mundo ficticio de las fábulas. Es este error de juicio lo que caracteriza al personaje como loco (353355). Por lo tanto; "en el marco [aristotélico] de una mimesis obligada a decir la verdad, la ficción de caballería, que en sí es denegación de la historia, y por consiguiente de la verdad, se presenta como una locura de la literatura: una historia delirante que le devuelve a don Quijote la imagen de su propio delirio" (355).

Molho concluye que "la historia [recobra] sus derechos con la muerte del protagonista", ya que por medio de ella se "elimina caballería y locura juntamente, en beneficio de una razón por fin presentida" (356).

En otras palabras: en el Quijote la historia es consustancial a la verdad (o experiencia en acto), cuya percepción diáfana equivale a cordura (o razón precartesiana). Correlativamente, el mundo de la poesía (en este caso, la ficción caballeresca) comporta la mentira (o fabulación falsificadora de la experiencia), cuya percepción equívoca deviene locura. Así, la falta de juicio del protagonista resulta de confundir la historia experiencial con la historia delirante (esto es, la ficción caballeresca o locura de la literatura). De ahí la necesidad de que muera el personaje, pues con él muere su falta de juicio y se clausura aquello que la origina, las novelas de caballerías.

Revisemos ahora el estudio que dedica a Margit Frenk. En "Ilusión y engaño de los sentidos en Don Quijote", Molho distingue dos modalidades de ilusión quijotesca, las cuales corresponden a las dos partes de la obra: una "ilusión delirante" que altera y transforma la percepción del mundo sensible (en un molino el protagonista ve un gigante, en una venta, un castillo) y una "ilusión paradójica" a través de la que se perciben correctamente las cosas pero se interpretan erróneamente (don Quijote primero ve una labradora y luego la concibe como Dulcinea encantada; ve un barco a orillas del Ebro que abordará como encantado) (Molho [1989] 2005b: 468). 
Ambas maneras de ilusión se fincan en las dos modalidades de la Poética aristotélica concernientes a la mímesis; a saber, historia y poesía. Una mira hacia el caso particular de la experiencia, mientras la otra mira hacia el proyecto universal que se encierra en los seres (470). La ilusión delirante, que opera en el Quijote de 1605, consiste en sustituir un caso de experiencia - historia en acto- con una representación poética por medio de analogías: los molinos — caso de experienciason gigantes - concepto universal de fuerza- Así, al discurso poético de don Quijote responde el discurso histórico que encarna Sancho Panza, para quien los molinos son molinos, lo cual corrobora la instancia narradora (471). Más todavía: el protagonista yerra entre poesía e historia respecto de sí mismo, porque se concibe como ente poético universal representativo del heroísmo caballeresco. De hecho, todo el libro se construye sobre esa insalvable contradicción (472).

Propia del Quijote de 1615, la ilusión paradójica sobreimprime la representación errónea al testimonio verídico de la vista. En el caso ya referido de Dulcinea encantada, la labradora particular de la historia se convierte en falsificación de la verdad poética. Y don Quijote intenta resolver la paradoja recurriendo sistemáticamente al "encantador", especie de "malin génie" que restaura el equilibrio perturbado del mundo (474).

En el episodio del barco encantado - he aquí, finalmente, la respuesta a la profesora Frenk - discute la poesía (don Quijote) con la historia (Sancho). Para el primero la nave encantada, nave poética, codifica una sucesión de motivos (navegación milagrosa, fortaleza, enemigos, socorro a alguna persona); en cambio, para el escudero el barco es de pescadores. Lo mismo ocurre con el supuesto "castillo", que no es sino "aceña" a los ojos de Sancho, lo cual confirma una vez más la instancia narradora (475-477). Con todo, don Quijote no confunde el barco con otro objeto - al modo de ventas $=$ castillos o molinos $=$ gigantes - , pues dice que es un "barco", salvo que está encantado, a lo cual se suma el aspecto maléfico de los molineros: "como salían enharinados, y cubiertos los rostros y los vestidos del polvo de la harina, representaban una mala vista". De modo que la aventura, lejos de "marcar una regresión del personaje a sus delirios de 1605, representa la afirmación, dentro de su coherente locura, de un implacable rigor mental: si el barco es encan- 
tado, entonces el lugar adonde me ha de llevar ha de ser por fuerza una fortaleza o castillo" (Molho [1989] 2005b: 477).

Don Quijote recurre esta vez a la causalidad, no de uno, sino de dos encantadores para explicar el infeliz desenlace de la aventura, la última en que "el protagonista goza de su plena libertad de loco. En el capítulo siguiente (II, 30), aparece la Duquesa de amazona que ha venido a cazar a don Quijote para llevárselo preso al teatro de la burla. De ahí la posición que ocupa la aventura en la trama narrativa del Quijote de 1615: es un adiós a las armas y a la vida" (478).

Una observación más de Molho: la búsqueda de la razón en el libro pasa por una locura sin remisión — delirante o paradójica— hasta la hora de la muerte, en la que el protagonista dimite de su "utopía tópica", pues la historia recobra sus derechos devolviéndole "la representación, no ya ilusoria sino exacta, de su perecedera circunstancia" (474).

$* * *$

El año antepasado, es decir, veinticinco años después de ocurrida la anécdota referida, Margit Frenk publicó un libro (Cuatro ensayos sobre el 'Quijote') que cierra con un estudio acerca del mismo tema: "Don Quijote ¿muere cuerdo?”. La autora no hace referencia a los artículos de Molho y su punto de vista es diferente al de considerar la cordura postrera del personaje condición necesaria a las nociones cervantinas de historia y razón. Cabe aclarar por otra parte que la profesora Frenk no pretende contestar de manera inequívoca la pregunta que da título a su ensayo, pero su análisis inclina la balanza hacia los indicios textuales que confirmarían la locura definitiva del protagonista. Revisemos sus argumentos.

En ningún pasaje del libro, tampoco en el epígrafe del último capítulo, se nos dice que don Quijote cambiará de nombre ni que recuperará el juicio (Frenk 2013a: 49). Salvo él mismo, el cura y Sansón Carrasco en su epitafio, no hay quien asuma la cordura del personaje en dicho capítulo, incluyendo al narrador, a Cide Hamete y su pluma (51). Capítulos atrás, don Antonio Moreno y en otro momento don Diego de Miranda y su hijo don Lorenzo consideran definitiva e irremediable su locura (5253). Es más, el propio don Quijote incurre en promesas hiperbólicas y 
absurdas cuando asienta en su testamento, refiriéndose a Sancho, que "si, como estando yo loco fui parte para darle el gobierno de una ínsula, pudiera agora, estando cuerdo, darle el de un reino, se le diera" (54).

Frenk ve un síntoma aún más notable de insania en el pasaje del testamento en el que desheredaría a la sobrina, no sólo si se casara con un asiduo lector de libros de caballerías, sino con alguien que supiera de su sola existencia. Y agrega:

Los personajes de esas historias parecen seguir siendo para él seres de carne y hueso: "Ya soy enemigo de Amadís de Gaula y de toda la infinita caterva de su linaje" [...]. Obsérvese que es justo después de estas palabras cuando sus amigos "creyeron sin duda que alguna nueva locura le había tomado" [...]. Y con razón. ¿No vemos aquí nuevamente, aunque de signo contrario, un don Quijote que enloquece en cuanto toca cosas referentes a la caballería? (54-55).

Más sutil se vuelve el análisis cuando dirige nuestra atención hacia el cuento de "La casa de locos de Sevilla" que narra el barbero en el primer capítulo de la Segunda parte. Sintomáticamente, el cuento ofende a don Quijote; ${ }^{1}$ además, éste y el licenciado loco experimentan "lúcidos intervalos" ${ }^{\prime 2}$, por si algo faltara, ambos declaran que recobraron el juicio "por la misericordia de Dios". Así, el

${ }^{1}$ Recuérdese que el licenciado loco, intentando salir de su confinamiento, escribe al arzobispo de Sevilla "con muy concertadas razones" que ha recobrado el juicio. El arzobispo envía a un capellán al manicomio para examinarlo, el cual es persuadido por la aparente cordura del licenciado. Éste, a punto de salir de su encierro, se despide de sus compañeros. Uno de ellos intenta retenerlo con la amenaza de no llover sobre la ciudad durante tres años, pues es el mismísimo Júpiter. Entonces, el licenciado le dice al capellán que si el otro es Júpiter y no quiere llover, "[yo] soy Neptuno" y "lloveré todas las veces que se me antojare". En resolución, "denudaron al licenciado, quedose en casa, y acabose el cuento". Sobreviene en este punto la reacción de don Quijote: "Yo, señor barbero, no soy Neptuno, el dios de las aguas, ni procuro que nadie me tenga por discreto no lo siendo". Y más adelante: "y si Júpiter, como ha dicho el barbero, no lloviere, aquí estoy yo, que lloveré cuando se me antojare. Digo esto porque sepa el señor Bacía que le entiendo" (II, 1, 47-49; aquí y en adelante cito el Quijote en la edición de Luis Andrés Murillo y consigno entre paréntesis la parte de la obra, el capítulo y las páginas).

${ }^{2}$ En el Tesoro de Covarrubias se consigna al respecto: "Loco atreguado, el que tiene dilucidos intervalos, haziendo treguas con él la locura". 
paralelismo entre los dos momentos es evidente: concertadas razones, que convencen a quien(es) lo escucha(n) de un retorno a la cordura y luego nueva caída en picada al abismo de la locura. Esta caída es ciertamente más abrupta en el caso del pobre loco sevillano, quien, como el don Quijote de Avellaneda — y la analogía no puede ser casual—, acabará su vida encerrado en un manicomio (Frenk 2013a: 56).

Frenk sugiere asimismo que Cervantes, después de leer a Avellaneda, en el primer capítulo de la Segunda parte traza un dilatado arco hacia el último capítulo, poniendo "en boca del barbero ese cuento que, ofensivo para don Quijote, se le quedó grabado en la memoria" (57). $Y$ añade: si tal cuento es una clave para comprender el cierre de la obra, el personaje "muere loco".

En sentido opuesto, identifica los siguientes indicios de cordura final: la lucidez del protagonista a la hora de anunciar su muerte y pedir un confesor y un escribano (50); el hecho de que los lectores antiguos y modernos le creemos cuando asevera reiteradamente que está cuerdo, olvidándosenos, no obstante, que se trata de un "loco-cuerdo" (52); y por último la convicción de lectores avezados para quienes don Quijote finalmente recupera el juicio, Borges entre ellos (57 n. 4). Con todo, a pesar de que los indicios de locura definitiva, como ya dije, tienen mayor peso, la autora concluye que Cervantes "quiso dejar abiertas ambas posibilidades" (58).

En mi opinión, el argumento más significativo que aporta Margit Frenk a favor de la locura irremediable se concentra en las analogías que descubre entre las locuras de don Quijote y del licenciado sevillano. Por ello, es más que oportuno detenernos en las observaciones de Maurice Molho sobre el caso. Me refiero a un artículo suyo publicado en 1991, "Para una lectura psicológica de los cuentecillos de locos del segundo Quijote". Cito:

De todas las especies [de seres vivos], la más frágil sin duda ninguna es el esquizofrénico. Si se ve constreñido a cambiar su área o territorio, el trauma puede ser tal que al instante precisa construir una identidad nueva [...]. [El problema] es su casi imposibilidad de asociar representación de palabra y representación de cosa (Freud, Metapsicología). Forma cuerpo con las cosas que lo circundan hasta el extremo que le confiere su iden- 
tidad, es decir el personaje que por fuerza ha de ser en función de ella. Un enfermo $\mathrm{E}$ - me dice un psiquiatra - tiene que desplazarse hacia la cocina. No dirá: "Voy a la cocina", sino: "Soy el cocinero". [...] Obsérvese que [...] el esquizofrénico identifica al personaje en que se invierte, con una función que es la que asume correlativamente a su circunstancia: circunstancia, personaje y función son, por así decirlo, indisociables (Molho [1991] 2005c: 74).

A partir de estas consideraciones, Molho descodifica los tres cuentos del Quijote de 1615: los dos del Prólogo (cuento del "loco hincha-perros" y del "loco aplasta-perros") y el referido del primer capítulo. Asimismo, atribuye a Cervantes los del Prólogo y nos aclara que el cuento narrado por el barbero, "que es a la vez el más desarrollado y el más sencillo", figuraba ya en colecciones impresas, así en el Libro de chistes de Luis de Pinedo como en los Cuentos de Arguijo.

Los tres suscitan casos emparentados con la esquizofrenia. Vayamos al análisis del tercero, el comentado por Margit Frenk. Su finalidad, asevera Molho, no es otra que señalar por boca del barbero que la locura es incurable. No obstante, el protagonista - licenciado de Osunadefiende la tesis de que la falta de juicio procede de tener los locos "los estómagos vacíos y los celebros llenos de aire". Por eso promete a sus camaradas enviarles regalos que coman, pues "el descaecimiento en los infortunios apoca la salud y acarrea la muerte". "¿De qué descaecimiento y de qué infortunios se trata si no del 'recogimiento' en los asilos y hospicios en los que la demencia no conoce más cura que la humillación y malos tratos? La reflexión crítica del licenciado loco bien podría ser una réplica al despiadado barbero" (77).

Si Molho está en lo cierto, en este pasaje del libro se plantea la posibilidad de la curación de la locura. Ahora bien, ¿cuáles son los territorios a los que adhieren su identidad los locos del cuento? Para uno de ellos, quien se cree Júpiter, el manicomio es un Olimpo gobernado por sus rayos. Y para el licenciado, quien se sabe Neptuno, es un Olimpo gobernado por sus aguas. Uno ve en el otro no más que un súbdito, de ahí que el loco-Júpiter amenace con destruir no sólo al de Osuna, sino a toda Sevilla por el pecado de lesa majestad que constituye su salida del manicomio-Olimpo. Ante esta negativa del derecho a su propia libertad, 
esto es, a la salud, el licenciado-Neptuno amenaza con llover las veces que se le antoje.

Todo en el cuento, la lenta narración, los morosos desarrollos internos, conduce al desenlace que sabemos, el cual se funda "en la voluntad oculta o inconsciente" del licenciado de "no desprenderse de un territorio con el que se identifica mediante su personaje y su función" (79). Así, se frustra su intento consciente de volver a casa, que "es precisamente lo que no hace".

Podría decir que las páginas precedentes abarcan el corpus de estudios derivados tal vez de aquella conversación iniciada en los pasillos de El Colegio de México, con excepción del artículo “¿Por qué se vuelve loco don Quijote?", publicado ese mismo año de 1988. (Nótese de paso que a este título pareciera responder, también interrogativamente, cerrando el ciclo temático un cuarto de siglo después, este otro: "Don Quijote imuere cuerdo?") No obstante, prefiero decirlo así: en 2013 se pierden las huellas tipográficas que — transformándolo progresivamente - retienen el diálogo de viva voz ocurrido entre Margit Frenk y Maurice Molho, diálogo seminal, efímero y a la vez memorable.

En adelante apostillaré los estudios citados con la intención de identificar posibles entrecruzamientos, concordancias y vías de interpretación en el marco siempre dilatado de la locura quijotesca.

Molho descodifica, como hemos visto, dos tipos de ilusión en sendas partes del Quijote, una caracterizada por la alucinación (ventas = castillos, molinos = gigantes) y otra por la paradoja que implica percibir correctamente las cosas y luego malinterpretarlas (un barco es un barco, salvo que está encantado). Diríase que el primer tipo pone en crisis la relación del protagonista con los entes del mundo; en cambio, en el segundo tipo lo que hace crisis es la puesta en discurso de dichos entes. ${ }^{3}$ De ahí el

${ }^{3}$ Nadie ha planteado mejor el problema que Michel Foucault en Les mots et les choses: "Don Quichotte est la première des oeuvres modernes puisqu'on y voit la raison cruelle des identités et des différences se jouer à l'infini des signes et des similitudes; puisque le langage y rompt sa vieille parenté avec les choses, pour entrer 
paso de la violencia física, tan frecuente en la Primera parte, a la agonística verbal de 1615 .

Detengámonos ahora en algunos indicios de la dinámica de la sinrazón paradójica, primero en don Quijote y luego en la instancia diegética. Se recordará que en el pasaje de "Las cortes de la muerte" un cochero disfrazado de diablo explica al protagonista los papeles representados por él y por sus compañeros, "recitantes" todos de la compañía de Angulo el Malo. Acto seguido, don Quijote hace un comentario que muestra de la manera más explícita su voluntad de percibir claramente las cosas: "-Por la fe de caballero andante [...] que así como vi este carro imaginé que alguna grande aventura se me ofrecía; y ahora digo que es menester tocar las apariencias con la mano para dar lugar al desengaño" (II, 11: 117; las cursivas son mías).

Ya instalado en el teatro de burlas montado por los duques, don Quijote, en un nivel más complejo, separa la realidad de la apariencia engañosa: "el rostro de la Dolorida es el del mayordomo, pero no por eso el mayordomo es la Dolorida, que a serlo, implicaría contradicción muy grande" (II, 44: 367). Y luego de ser arrollado junto a Sancho por un tropel de toros bravos, razona así: "cuando esperaba palmas, triunfos y coronas, granjeadas y merecidas por mis valerosas hazañas, me he visto esta mañana pisado y acoceado y molido de los pies de animales inmundos y soeces" (II, 59: 482).

Adviértase aquí lo siguiente: para él los toros son eso, animales, por lo cual el reconocimiento de su estado maltrecho desdice de manera consciente su autoimagen poética. Además, no recurre como acostumbra al expediente de los encantadores para explicar el fracaso de la aventura.

Diseminados con cálculo y no al azar, los indicios citados muestran en la superficie de la trama la progresiva clausura de caminos hacia la utopía tópica. Y en paralelo muestran la creciente aproximación al juicio "libre y claro" que el protagonista pregona hacia el final del libro. La poesía - en palabras de Molho - va cediendo a los imperativos de la historia y, entrecruzados, los dos grandes temas del Quijote - caballería y locura- comienzan a cerrarse.

dans cette souveraineté solitaire d'où il ne reapparaîtra, en son être abrupt, que devenu litterature" (62). 
De su lado, el narrador ${ }^{4}$ nos hace notar una y otra vez la ausencia de delirios a lo largo de la Segunda parte. Por ejemplo, al cabo del capítulo 24, allí donde dice que señor y escudero "llegaron a la venta [...] y no sin gusto de Sancho, por ver que su señor la juzgó por verdadera venta, y no por castillo, como solía" (II, 24: 484). O hacia el final del libro, cuando el narrador sugiere la superación gradual de la locura: “Apeáronse en un mesón, que por tal le reconoció don Quijote, y no por castillo de cava honda, torres, rastrillos y puente levadiza, que después que le vencieron con más juicio en todas las cosas discurría, como agora se dirá" (II, 71: 574; son mías las cursivas).

Los indicios citados documentan la ilusión paradójica, una ilusión diferente de la alucinatoria según lo muestran las reacciones del personaje y las llamadas de atención que el narrador hace sobre las mismas. Pero las cosas no paran allí: este último, acabamos de observarlo, introduce una prolepsis que apunta hacia la cordura final de don Quijote. Y si remontamos unos cuantos capítulos descubrimos - justo cuando ha sufrido la derrota definitiva a manos del Caballero de la Blanca Luna-, no los designios, sino los deseos del narrador: "Sancho, todo triste $[. .$.$] parecíale que todo aquel suceso pasaba en sueños y que toda$ aquella máquina era cosa de encantamento. Veía a su señor rendido [...] imaginaba la luz de la gloria de sus hazañas escurecida [...]. Temía si quedaría o no contrecho Rocinante, o deslocado su amo, que no fuera poca ventura si deslocado quedara" (II, 64: 535).

${ }^{4}$ Me refiero a la instancia diegética que asume la primera persona del singular desde la primera frase ("En un lugar de la Mancha, de cuyo nombre no quiero acordarme"; I, 1) hasta el deceso del personaje ("don Quijote [...] entre compasiones y lágrimas de los que allí se hallaron, dio su espíritu, quiero decir que se murió"; II, 74; las cursivas son mías). Al respecto, Michel Moner ha trazado una ruta de salida del laberinto de autores y narradores diseñado por Cervantes: "De fait, il s'agit là d'un nouvel imbroglio, parfaitement indémêlable. Mais une chose est certaine: il n'y a pas de véritable solution de continuité entre les premiers chapitres — diégétiques? - et les suivants — métadiégétiques? - imputés à Cide Hamete Benengeli. L'histoire de Don Quichotte est, en effet, comme on vient de le voir, contrôlée de bout en bout par une voix qui se trouve «derrière» le chroniqueur maure et dont on conviendra qu'elle a toutes chances d'appartenir à un narrateur extradiégétique distinct de Cide [...]. De part et d'autre du duel avec le Biscayen, l'histoire de Don Quichotte n'est jamais donnée que comme une réécriture, un palimpseste prodigieux où Cide Hamete Benengeli, ni tout à fait narrateur, ni tout à fait personnage, n'est, peut-être, en définitive, qu'un distributeur d'apostilles" (90-91). 
Aunque revestida de humor, la dilogía facilitada por el estilo libre indirecto es nítida: Sancho teme que su señor resulte "dislocado" como contrahecho Rocinante, mientras que la instancia diegética lo quiere "deslocado", 'sano de locura'. Esta trayectoria en retrospectiva nos lleva hasta el capítulo 29, ése en el que Margit Frenk notaba una recaída en las alucinaciones de la Primera parte y Molho, la clave de la ilusión paradójica de la Segunda parte.

Prestemos primero atención al epígrafe del capítulo: "De la famosa aventura del barco encantado". Adjetivando al barco como "encantado", el narrador remite a los virtuales lectores u oyentes al motivo folclórico en el que una nave conduce al héroe, solo, hacia lugares maravillosos. Al mismo tiempo, sitúa a don Quijote en un contexto que le impone acciones específicas cuya realización parece no necesitar de su alucinación: "-Has de saber, Sancho, que este barco que aquí está, derechamente y sin poder ser otra cosa en contrario, me está llamando y convidando a que entre en él y vaya en él a dar socorro a algún caballero o a otra necesitada y principal persona que debe de estar puesta en alguna grande cuita. Porque éste es estilo de los libros de las historias caballerescas" (II, 29: 262).

No la percepción clara del objeto (barco), sino la interpretación de su sentido (barco encantado) mediante una determinada puesta en discurso (el estilo de las historias caballerescas) es lo que caracteriza la insania del personaje, quien una vez a bordo escuchará al escudero anticipar el desenlace: "la locura que nos aparta de vosotros [les dice al rucio y a Rocinante], convertida en desengaño, nos vuelva a vuestra presencia!" (II, 29: 263). Pero, ¿en qué consiste esta vez el desengaño? El imaginado castillo resulta ser una aceña y la canalla malvada, molineros enharinados, lo cual reconoce don Quijote porque acepta "con gran sosiego" pagar el barco que acaba de destrozar. Sin embargo, el desengaño es mucho más hondo y ocurre cuando lleva hasta la aporía el manido recurso con que resuelve las paradojas generadas por sus interpretaciones erróneas: "en esta aventura [dice "entre sí"] se deben de haber encontrado dos valientes encantadores, y el uno estorba lo que el otro intenta: el uno me deparó el barco y el otro dio conmigo al través" (II, 29: 267). Y luego: "Dios lo remedie, que todo este mundo es máquinas y trazas, contrarias unas de otras. Yo no puedo más". Bien lo ha observado Molho: 
esta aventura es un adiós a las armas y a la vida, es decir, a la plena libertad del loco.

Vista en perspectiva, la ilusión paradójica prepara el advenimiento del personaje, no a la razón moderna, sino al juicio "libre y claro" de Alonso Quijano el Bueno, ${ }^{5}$ trasunto de aquel remoto lector ávido de apellido vacilante: Quijada o Quesada o Quejana. Asimismo, el desvanecimiento de la utopía tópica caballeresca es simultáneo del de la locura, y ambos - encarnados por el personaje y señalados por el narrador-se inician en la aventura del barco encantado, allí donde don Quijote dice "entre sí", en soliloquio, ${ }^{6}$ a modo de autoconfesión, "Yo no puedo más". Todo lo cual nos conduciría a concluir que el libro ha de cerrarse necesariamente con un don Quijote cuerdo. Y ya lo vimos, para Mollho la muerte del protagonista es indisociable de su cordura, bien porque se "elimina caballería y locura juntamente", bien porque la historia recobra sus derechos devolviéndole a don Quijote "la representación, no ya ilusoria sino exacta, de su perecedera circunstancia".

Así, la cordura postrera sería inmanente a la dinámica de la ilusión paradójica, la cual recusa las alucinaciones — cosa versus nombre- y busca sin encontrar nuevas relaciones entre el lenguaje y el mundo. Sin embargo, nada parece haber en dicha dinámica que vuelva indisociables cordura y muerte del protagonista. ¿Recobra el juicio — si es que lo recobra - para decir que se siente "a punto de muerte", hacer su testamento y confesarse? Vayamos por partes. Al inicio del capítulo final, el narrador informa que a don Quijote se le arraigó una calentura que lo tuvo en cama seis días "ya fuese de la melancolía que le causaba el

${ }^{5}$ Para el cambio de nombre del personaje, véase el estudio de Margit Frenk titulado “Alonso Quijano no era su nombre”, en Cuatro ensayos sobre el 'Quijote'.

${ }^{6}$ En el Quijote, "decir entre sí” y sus variantes ("para sí”, "para mí” o bien "leer para s'́, etc.) no implican silencio, sino voz baja, murmurante, de ahí que al final del soliloquio de don Quijote el narrador apunte: "Y alzando la voz, prosiguió diciendo". Pongo otros ejemplos. "[A] hora me acuerdo haberle oído decir muchas veces, hablando entre sí, que quería hacerse caballero andante", dice el ama al cura y al barbero (I, 5: 107). Y a pregunta de su señor: “¿Qué murmuras, Sancho?”, este responde: "No digo nada, ni murmuro de nada [...] sólo estaba diciendo entre mí que quisiera haber oído lo que vuesa merced [...]" (II, 22: 204). Para la técnica de lectura del protagonista, véase Gustavo Illades, “Aquellas sonadas soñadas invenciones que leía': de la lectura susurrante de Quejana a la locura de don Quijote". 
verse vencido, o ya por la disposición del cielo, que así lo ordenaba". Por su parte, el cura, el barbero, Sansón Carrasco y Sancho atribuyen la fiebre a la pesadumbre de verse vencido y de no cumplir su deseo de desencantar a Dulcinea. Alarmados pues sus amigos, llaman al médico, quien le toma el pulso y aconseja que "por sí o por no" atienda "a la salud de su alma, porque la del cuerpo corría peligro". Además, coincide con el narrador y con los amigos en que "melancolías y desabrimientos le acababan", todo lo cual se dice en estilo indirecto.

En suma, estos inequívocos signos de muerte a causa de la melancolía son previos al sueño que le devuelve un juicio "libre y claro". En otras palabras: va a morir sin que se hayan eliminado "caballería y locura juntamente". Adicionalmente, sabe que está en peligro de muerte y lo acepta, pues escucha el dictamen médico "con ánimo sosegado". Así que antes de su sanación onírica - y no después - tiene la representación exacta de su perecedera circunstancia. Por lo tanto, cordura y muerte son disociables; de hecho, esta última parece ser contingente, producto de la lectura cervantina del Quijote apócrifo. De ahí que el cura, en el instante mismo en que fenece su amigo, pide al escribano dar testimonio de la muerte natural de Alonso Quijano el Bueno, "llamado comúnmente don Quijote de la Mancha" para "quitar la ocasión de algún otro autor que Cide Hamete Benengeli le resucitase falsamente, y hiciese inacabables historias de sus hazañas". ${ }^{7}$ En el mismo sentido discurre el propio Cide a lo largo del explicit con que cierra el libro. Se recordará que ordena a su pluma advertir al "escritor fingido y tordesillesco": "Que deje reposar en la sepultura los cansados y ya podridos huesos de don Quijote, y no le quiera llevar, contra todos los fueros de la muerte, a Castilla la Vieja; haciéndole salir de la fuesa donde real y verdaderamente yace tendido de largo a largo, imposibilitado de hacer tercera jornada y salida nueva" (II, 74: 592-593).

Bien es sabido que estas líneas se deben a que Avellaneda amaga con proseguir las aventuras de don Quijote en Castilla la Vieja, para lo cual habría tenido que sacarlo de la Casa del Nuncio, el manicomio de Toledo donde lo dejó encerrado al cierre de su continuación apócrifa.

${ }^{7}$ No me decido a optar por una de las siguientes lecturas: el cura hace una broma inoportuna al máximo o bien acusa ya el contagio de la locura quijotesca. 
Aunque no es posible responderla, se impone la pregunta: ¿finalizaría la Segunda parte con un don Quijote/Alonso Quijano vivo de no haberse dado la intromisión del escritor tordesillesco? En cualquier caso, es indudable que mediante la muerte del personaje Cervantes secó el tintero a nuevos Avellanedas.

Margit Frenk asevera que en ningún pasaje del Quijote, incluido el epígrafe del último capítulo, se dice que el protagonista cambiará de nombre ni que recuperará el juicio. ${ }^{8}$ Es cierto, como también lo es el que en ninguna parte el narrador - no incluyo a los personajes - anticipa de manera inequívoca lo contrario. De hecho, según observamos ya, hace notar que discurre "con más juicio en todas las cosas" luego de su derrota definitiva y también expresa su deseo de un don Quijote "deslocado". En este punto los lectores pisamos, por así decir, suelos lábiles.

Por otra parte, los diversos indicios de locura definitiva que Frenk identifica con gran perspicacia nos abren el camino hacia otros más. Mencionaré algunos a partir de su observación según la cual ningún personaje - con excepción de don Quijote, el cura y Sansón Carrasco en su epitafio - , ni el narrador, ni Cide Hamete o su pluma asumen que recupera la cordura. En primer lugar prestemos atención al comentario hecho ante el cadáver por el representante de la autoridad civil: "Hallose el escribano presente y dijo que nunca había leído en ningún libro de caballerías que algún caballero andante hubiese muerto en su lecho tan sosegadamente y tan cristiano como don Quijote" (II, 74: 591). ¿Cuál es el propósito de este comentario? Dar a entender que quien muere no es Alonso Quijano el Bueno, es decir, el cuerdo, sino el caballero andante, el cristiano loco.

${ }^{8}$ Asimismo, anunciar en el epígrafe la recuperación de la cordura quitaría toda sorpresa a la manera como ocurre: después de un dilatado sueño, don Quijote despierta y, "dando una gran voz”, dice: “¡Bendito sea el poderoso Dios, que tanto bien me ha hecho!”. Además, tomemos en cuenta que no son infrecuentes los epígrafes en que se evita anticipar sucesos de hondo calado, así el de la derrota final del personaje (II, 64). 
En segundo lugar, el nivel diegético conduce al escribano. Ciertamente, en el discurso que Cide presta a la pluma se hace referencia a "los cansados y ya podridos huesos de don Quijote". De nueva cuenta es el caballero andante quien muere, no el hidalgo manchego. Por último, revisemos el punto de vista del narrador subsecuente a la supuesta curación onírica del protagonista. Cito en orden lineal las intervenciones diegéticas que hacen al caso. "Miráronse [los amigos] unos a otros, admirados de las razones de don Quijote"; "en tanto que don Quijote fue Alonso Quijano el Bueno, a secas, y en tanto que fue don Quijote de la Mancha, fue siempre de apacible condición y de agradable trato"; "después de haber hecho la cabeza del testamento y ordenado su alma don Quijote"; "llegó el último [día] de don Quijote"; "Este fin tuvo el ingenioso hidalgo de la Mancha"; "Déjanse de poner aquí los llantos de Sancho, sobrina y ama de don Quijote". Y una última: "mi verdadero don Quijote", enunciada por Cide para algunos críticos y editores y, para otros, por el narrador, quien, dicho sea de paso, relevaría al historiador moro mediante una metalepsis inusitada, pues el cambio de instancias narrativas carece de marcas textuales en la editio princeps.

Como se ve, la mayoría de las intervenciones del narrador implican que la muerte le acontece al desquiciado caballero andante. Sólo en una ocasión se nombra a "Alonso Quijano el Bueno, a secas", tercer nombre del protagonista. No obstante, el pasaje es descartable porque contiene uno más de los juegos de equívocos que tanto complacían a Cervantes. Me explico: don Quijote nunca fue Alonso Quijano, sino un tal Quijada o Quesada o Quejana. Notemos también la antífrasis que supone atribuir al belicoso, irascible e intransigente personaje una "apacible condición" y "agradable trato" - "en tanto que don Quijote"-, no en ciertas ocasiones, sino "siempre". Y en lo que respecta a la mención al "ingenioso hidalgo", ese lector compulsivo que da título a la Primera parte, deja abierta la disyuntiva que venimos observando entre cordura final y locura irremediable.

Por otro lado, cuando Frenk identifica similitudes entre don Quijote y el licenciado de Osuna, comenta que éste, como el protagonista de Avellaneda, acabará sus días en un manicomio. Y agrega en abono de la hipótesis acerca de la locura definitiva: "la analogía no puede ser casual". 
Sin embargo, su observación podría reforzar la hipótesis contraria, pues en diversos pasajes de la Segunda parte narrador y personajes, allí donde se ofrece la ocasión, contradicen al autor tordesillesco con el propósito evidente de demostrar el carácter apócrifo de su novela. Pongo uno de los ejemplos más célebres: cierto día en que don Quijote sale de una venta se informa enseguida acerca de "cuál era el más derecho camino para ir a Barcelona sin tocar en Zaragoza: tal era el deseo que tenía de sacar mentiroso aquel nuevo historiador [Avellaneda] que tanto decían que le vituperaba" (II, 60: 491).

Por lo tanto, resulta verosímil concluir que la cordura final del personaje daría el mentís definitivo al autor tordesillesco, así como su muerte atajó posibles continuaciones de la obra cervantina. En apoyo de lo anterior, y sin asociar cordura a muerte, vuelvo a una observación de Molho respecto de los cuentecillos sobre esquizofrénicos que aparecen en el inicio de la Segunda parte (adviértase que no incluye a don Quijote entre quienes padecen esquizofrenia): el desenlace del cuento del licenciado frustra su intento consciente de volver a casa, que "es precisamente lo que no hace". Y don Quijote, agrego yo, antes de autotransformarse en Alonso Quijano el Bueno, lo que precisamente sí hace y por voluntad propia es volver a casa.

Con todo, son más que convincentes los indicios de locura definitiva identificados por Margit Frenk.

III

Iniciado en aquella lejana mañana de 1988, el diálogo entre Frenk y Molho sobre los delirios quijotescos derivaría, andando el tiempo, en profundas y originales reflexiones acerca de la muerte del protagonista, sea como punto final de una locura incurable o como condición indispensable a un nuevo tipo de razón.

Con base en las apostillas precedentes considero que ambas perspectivas son esclarecedoras y no necesariamente excluyentes. Pero, ¿cómo armonizarlas? Retomemos los hechos y dichos relativos al extraordinario suceso onírico aludido por don Quijote, quien duerme "de un tirón, 
como dicen, más de seis horas; ${ }^{9}$ tanto que pensaron el ama y la sobrina que se había de quedar en el sueño". En cuanto despierta vocifera: “¡Bendito sea el poderoso Dios, que tanto bien me ha hecho!”. Después, interrogado por la sobrina, explica a ésta las "misericordias" que Dios "ha usado" con él: "Yo tengo juicio ya libre y claro, sin las sombras caliginosas de la ignorancia, que sobre él me pusieron mi amarga y continua leyenda de los detestables libros de las caballerías [...] y no me pesa sino que este desengaño ha llegado tan tarde, que no me deja tiempo para hacer alguna recompensa leyendo otros que sean luz del alma" (II, 74: 587).

Acto seguido, solicita hablar con sus amigos - el cura, Sansón Carrasco y maese Nicolás - , a quienes pide "albricias" porque ya no es don Quijote de la Mancha, sino Alonso Quijano el Bueno. Después de oírlo, aquellos "creyeron, sin duda, que alguna nueva locura le había tomado". Pero él argumenta que el cielo lo ha ayudado, que se siente a punto de morir y que "en tales trances como éste no se ha de burlar el hombre con el alma". En fin, una de las señales por las que los amigos "conjeturaron se moría fue el haber vuelto con tanta facilidad de loco a cuerdo". ${ }^{10}$ Y la prueba de su cordura fueron las razones que añadía, "tan cristianas y con tanto concierto". De su lado, el narrador desliza una precisión punzante cuando en presencia del escribano, hecha ya la cabeza del testamento, don Quijote ordena su alma "con todas aquellas circunstancias cristianas que se requieren".

En síntesis, el personaje, según él mismo, experimenta un sueño revelador - inaccesible para nosotros - que le devuelve el juicio gracias a las misericordias de Dios. Por ello detesta ya los libros de caballerías y asimismo lamenta no tener tiempo de entregarse a la lectura de libros devotos. Para muchos lectores u oyentes de la época bien podría tratarse de un suceso providencial aunque ficticio, de un milagro, pero narrador y personajes - significativamente el cura - se abstienen de interpretar el suceso como intervención divina.

${ }^{9}$ Siguiendo a Iriarte y a Green, Murillo anota: "la calentura y este largo dormir nos dan como el diagnóstico del trance que conduce a la normalidad mental y a la muerte, según teorías del doctor Huarte de San Juan" (II, 74: 587 n. 6).

${ }_{10}$ Transcribo la nota de Murillo: "La conjetura se fundaba en la opinión común de que los locos suelen recobrar el juicio para morirse" (II, 74: 588 n. 10). 
Puestas las cosas en perspectiva puede afirmarse que la versión del protagonista queda aislada, pues los amigos se limitan a creer que ha recuperado la cordura porque razona cristiana y concertadamente. De su lado, el narrador se distancia por completo cuando delega en don Quijote el anuncio de su cordura, cordura que la misma instancia diegética ni acredita ni desautoriza. Y también se distancia de la certidumbre cristiana de los amigos cuando desliza la frase arriba citada: don Quijote ordena su alma, es decir, se confiesa "con todas aquellas circunstancias cristianas que se requieren". Si bien se ve, para el narrador el requerimiento no es más que una convención y el credo, algo circunstancial con lo que parece no identificarse.

La nueva identidad del protagonista lo lleva a cambiar una segunda vez de nombre, autodenominándose "Alonso Quijano, a quien mis costumbres me dieron renombre de Bueno". Vale decir, se reintegra al lector abismado de apellido vacilante de la Primera parte, pero con una diferencia sustancial: ahora repele los libros de caballerías y desea leer los de devoción cristiana, "que sean luz del alma", haría de no sentir que se va "muriendo a toda priesa". En esto consiste la recuperación de su juicio "libre y claro". Nos hallamos pues, ante un nuevo avatar del lector insaciable cuya vocación mimética lo proyectaría a identificarse esta vez, no con Amadís u Orlando, sino con personajes sacros. ${ }^{12}$ No por azar a lo largo del Quijote se diseminan variadas intersecciones de ambos campos semánticos, el novelesco de caballerías — que don Quijote asume como real y verdadero- y el religioso cristiano.

A continuación cito por falta de espacio unos cuantos pasajes de dichas intersecciones ocurridas en el mundo interior del personaje. En el temprano capítulo 13 de la Primera parte, explica a Vivaldo que "los religiosos, con toda paz y sosiego, piden al cielo el bien de la tierra", mientras que "los soldados y caballeros ponemos en ejecución lo que ellos piden [...]. Así que somos ministros de Dios en la tierra y brazos por quien se ejecuta en ella su justicia”. En diálogo con Sancho, eleva

${ }^{11}$ Consúltese la nota de Murillo (II, 62: 520 n. 29).

12 Para las analogías entre las técnicas de lectura monacal en la Edad Media y las del personaje cervantino, véase el artículo ya referido "Aquellas sonadas soñadas invenciones que leía': de la lectura susurrante de Quejana a la locura de don Quijote”. 
el ministerio de los caballeros andantes: "pero no todos podemos ser frailes, y muchos son los caminos por donde lleva Dios a los suyos al cielo: religión es la caballería; caballeros santos hay en la gloria" (II, 8: 98-99). Cuando doña Rodríguez con apariencia de fantasma entra en su habitación, exclama: “- $-[\ldots]$ soy católico cristiano y amigo de hacer bien a todo el mundo; que para esto tomé la orden de caballería andante que profeso, cuyo ejercicio aun hasta hacer bien a las ánimas de purgatorio se estiende" (II, 48: 397).

Hacia el final del libro promete la gloria al mismísimo bandolero Roque Guinart: “- $-[\ldots]$ si vuestra merced quiere ahorrar camino y ponerse con facilidad en el de su salvación, véngase conmigo, que yo le enseñaré a ser caballero andante, donde se pasan tantos trabajos y desventuras, que, tomándolas por penitencia, en dos paletas le pondrán en el cielo" (II, 60: 501-502).

Dialogando con el cura y maese Nicolás acerca de la existencia real y no ficticia de los caballeros andantes novelescos, el barbero le pregunta con malicia sobre la estatura del gigante Morgante. A lo que don Quijote responde en clave teológica: “-En esto de los gigantes [...] hay diferentes opiniones, si los ha habido o no en el mundo; pero la Santa Escritura, que no puede faltar un átomo en la verdad, nos muestra que los hubo, contándonos la historia de aquel filisteazo de Golías, que tenía siete codos y medio de altura, que es una desmesurada grandeza" (II, 1: 50).

Baste con estos ejemplos para advertir que la locura quijotesca hace del caballero andante literario y del propio protagonista un brazo armado de Dios, no sólo en la Tierra, sino en el más allá, un instrumento de salvación de almas, una especie bélica de santo. Este conjunto de intersecciones entre campos semánticos antitéticos —recurso característico del arte barroco - termina fundiéndolos: don Quijote se eleva a sí mismo hasta una divinidad que, por inversión obligada, tiende a quijotizarse.

Si el análisis es plausible, el propósito explícito del libro ${ }^{13}$ comportaría un propósito implícito. Dicho en otros términos: en el Quijote se novela el caso de un lector mimético hasta la locura a través de varia-

13 El Prólogo de 1605 lo enuncia claramente: "derribar la máquina mal fundada destos caballerescos libros". Y al final del libro el explicit de Cide Hamete —o del narrador - lo da por realizado parcial pero inevitablemente: "no ha sido otro mi deseo que poner en aborrecimiento de los hombres las fingidas y disparatadas historias de los 
dos recursos de distanciamiento cuyo objetivo habría sido convertir al lector crédulo de libros caballerescos en lector crítico. ${ }^{14} \mathrm{Y}$ si la aventura del protagonista lo conduce a autodivinizarse al punto de quijotizar —en la medida que se quiera - el ámbito religioso, el propósito del libro involucra también al creyente crédulo, más aún, al supersticioso a quien engañaban con impunidad los echacuervos, como se cuenta en el Tractado Quinto del Lazarillo de Tormes. Cervantes, qué duda cabe, sabía bien para quiénes escribía. ¿Y nosotros? Quizá la respuesta se halle en la sentencia de un contemporáneo suyo, Martín González de Cellorigo, la cual nos recuerda Cristina Múgica (250): España —asevera Cellorigo - "es una república encantada con hombres que viven fuera del orden natural". ${ }^{15}$

En conclusión, Margit Frenk abre una vía de análisis al argumentar la muerte de un don Quijote sin juicio, salvo que, según intenté mostrar, se trata de otra versión de locura, esa que lo devuelve - bajo el nombre de Alonso Quijano el Bueno- a la república de hombres encantados. Asimismo, Maurice Molho descifra que al morir el protagonista se eliminan juntas caballería y locura en beneficio de una razón por fin presentida, una razón, agrego, propia del libro y no del héroe.

\section{BIBLIOGRAFÍA}

Cervantes, Miguel De. Segunda parte del ingenioso cauallero Don Quixote de la Mancha. Madrid: Juan de la Cuesta, 1615.

Cervantes, Miguel De. El ingenioso hidalgo don Quijote de la Mancha. Ed. Luis Andrés Murillo. Madrid: Castalia, $5^{\text {a }}$ ed., 2 t., 1987.

CovarRubias, Sebastián De. Tesoro de la lengua castellana o española [1611]. Ed. Martín de Riquer. Barcelona: Alta Fulla, 1993.

libros de caballerías, que por las de mi verdadero don Quijote van ya tropezando, y han de caer del todo, sin duda alguna" (II, 74: 593).

${ }^{14}$ Algunos de dichos recursos son los siguientes: desdoblamiento de la autoría, mezcla de géneros discursivos, intertextualidad explícita, interrupción e interpolación de relatos, humor y parodia, entrecruzamientos del mundo de los personajes con el mundo de los lectores, etcétera.

15 Citado en Pierre Vilar, "El tiempo del Quijote", en Crecimiento y desarrollo. Barcelona: Ariel, 1983. 
FrenK, Margit. “Don Quijote ¿muere cuerdo?”, en Cuatro ensayos sobre el 'Quijote'. México: Fondo de Cultura Económica, 2013a (Lengua y Estudios Literarios): 49-58.

FrenK, MARGIT. "Alonso Quijano no era su nombre", en Cuatro ensayos sobre el 'Quijote'. México: Fondo de Cultura Económica, 2013b (Lengua y Estudios Literarios): 37-47.

Foucault, Michel. Les mots et les choses, une archéologie des sciences humaines. Paris: Gallimard, 1966.

ILLADES, Gustavo. “'Aquellas sonadas soñadas invenciones que leía': de la lectura susurrante de Quejana a la locura de don Quijote", en Tus obras los rincones de la tierra descubren (Actas del VI Congreso Internacional de la Asociación de Cervantistas). José Manuel Lucía Megías et al. (eds.). Alcalá de Henares: Centro de Estudios Cervantinos, 2008: 367-377.

Molho, Maurice. “¿Por qué se vuelve loco don Quijote?”, en De Cervantes. Paris: Editions Hispaniques, 2005a: 349-356.

Molho, Maurice. "Ilusión y engaño de los sentidos en Don Quijote (De los molinos de viento al barco encantado)", en De Cervantes. Paris: Editions Hispaniques, 2005b: 467-478.

Molno, Maurice. "Para una lectura psicológica de los cuentecillos de locos del segundo Quijote", en De Cervantes. Paris: Editions Hispaniques, 2005c: $73-84$.

Moner, Michel. Cervantès conteur. Écrits et paroles. Madrid: Casa de Velázquez, 1989.

Múgica, Cristina. "Escritura y melancolía en el Quijote de 1605”, en El 'Quijote' desde América. Gustavo Illades y James Iffland (eds.). Puebla: Benemérita Universidad Autónoma de Puebla-El Colegio de México, 2006: 245-256. 